\title{
Challenging clinical and translational physiology
}

\author{
Heikki Veli Huikuri \\ Department of Internal Medicine, Institute of Clinical Medicine, University of Oulu, Oulu, Finland \\ *Correspondence: e-mail: heikki.huikuri@oulu.fi
}

The aims of any research effort in the field of physiology are to promote human health, to improve quality of life of individuals in addition to making new scientific discoveries, which may eventually open new fields of investigation. Novel research in physiology now provides new opportunities from translational research, e.g., from technology, engineering, behavioral sciences, biology, biochemistry, physics, as well as from basic research in genetics, genomics, and molecular research to epidemiology, prevention, and bedside clinical research. The combination of various scientific fields serves as a new approach to promote science, which has now been recognized also by the major funding organizations throughout the world (Berro et al., 2011; Bolon et al., 2011).

The main challenges in for clinical and translational physiology are to combine these new scientific approaches. There are few high-level international journals that directly combine research in these areas, i.e., basic physiology and its related research topics to clinical research and clinical practice. Most of the currently available physiology journals focus exclusively on the particular aspects of a given field of physiology usual without any emphasis on the clinical application of the results of these studies. On the other hand, most of the general medical journals and specialized clinical journals focus only on specific and relevant clinical problems in their own fields with little no emphasis on the underlying physiological abnormalities that give rise to disease. Therefore, Frontiers in Clinical and Translational Physiology will open new opportunities for those scientists who perform their research in physiology or translational areas of research with direct or indirect clinical applications.
The number of studies covered by this Journal are limitless. However, a few very general examples help illustrate the types of studies and interactions fall under the heading Frontiers in Clinical and Translational Physiology. Studies that combine research on autonomic neurosciences to clinical applications, or that link genome-wide association studies to risk stratification at the level of well-defined patient groups or general population samples. Other examples may include the combination of research on medical technology to clinical applications, new methods to be used in clinical practice, and to promote basic science discoveries into diagnostics and treatment as well clinical discoveries to clinical practice. Translational research also encompasses the effective movement of new knowledge to diagnosis and treatment of diseases. There have been many roadblocks to successful movement of these discoveries. One of these has been the lack of publication forums for translational research.

The aim of the journal is open a new platform for scientists from many fields of physiology, such as cardiovascular, gastrointestinal, liver, endocrinology, metabolism, renal, bone and muscle, cancer, psychiatric, cell, preventive, rehabilitation, and exercise physiology. The aim of translational part of the journal is to attract scientists from other fields of research, e.g., technology, engineering, behavioral sciences, psychology, biochemistry, physics, etc., who work in collaboration with clinical investigators. In addition, our aim is to attract clinical scientists who use methods or study designs based on physiology or translational sciences.

Closing gaps between the clinical, physiological, and translational research will be the main current challenge as well as the challenge for future research in attempts to promote science and human health. With the launch of Frontiers in Clinical and Translational Physiology, we provide new tools to meet these challenges. Open access, tiered publication in combination with interaction with the reviewers set the stage for optimal exchange of scientific information in this field. Many types of manuscripts are welcomed, including hypothesis generating articles, opinion articles, and mini-reviews in addition to more general original articles.

\section{REFERENCES}

Bolon, B., Altrock, B., Barthold, S. W., Baumgarth, N., Besselsen, D., Boivin, G., Boyd, K. L., Brayton, C., Califf, R. D., Couto, S., Eaton, K. A., Foreman, O., Griffey, S. M., LA Perle, K., Laimore, M. D., Liu, C., Meyerholz, D. K., Nikitin, A. Y., Schoeb, T. R., Schwahn, D., Sellers, R. S., Sundberg, J. P., Tolwani, R., Valli, V. E., and Zink, M. C. (2011). Advancing translational research. Science 33, 1516-1517.

Berro, M., Burnett, B. K., Fromell, G. J., Hartman, K. A., Rubinstein, E. P., Schuff, K. G., Speicher, L. A., and on behalf of the IND/IDE Taskforce of the Clinical and Translational Award Consortium, Support for investigator-initiated clinical research involving investigational drugs of devices. (2011). The clinical and translational science award experience. Acad. Med. 86, 217-223.

Received: 02 May 2011; accepted: 04 May 2011; published online: 16 May 2011.

Citation: Huikuri HV (2011) Challenging clinical and translational physiology. Front. Physio. 2:22. doi: 10.3389/ fphys.2011.00022

This article was submitted to Frontiers in Clinical and Translational Physiology, a specialty of Frontiers in Physiology.

Copyright $\odot 2011$ Huikuri. This is an open-access article subject to a non-exclusive license between the authors and Frontiers Media SA, which permits use, distribution and reproduction in other forums, provided the original authors and source are credited and other Frontiers conditions are complied with. 